\title{
Análise do potencial turístico da Festa do Divino Espírito Santo em Alcântara, Maranhão, Brasil
}

\author{
Analysis of the tourism potential "Festa do Divino Espirito Santo in Alcantara, \\ Brazil"
}

\author{
Karoliny Diniz Carvalho (CARVALHO, K. D.) ${ }^{*}$
}

RESUMO - No artigo se analisa o potencial turístico da Festa do Divino Espírito Santo no município de Alcântara, Maranhão (Brasil). No entendimento das relações entre festas populares e turismo, buscou-se a pesquisa qualitativa de caráter descritivo, pautada em dados bibliográficos e entrevistas com os organizadores da Festa. Com base em Guarinello (2001), Rangel (2002) e Hall (2001), no estudo se relaciona os conceitos de memória e identidade, apresentando os impactos positivos e negativos da atividade turística na cultura popular. Se analisa a dinâmica da Festa do Divino, ao tempo em que demonstra as possibilidades e desafios dessa manifestação cultural enquanto produto turístico de Alcântara, Maranhão. A pesquisa apontou para a necessidade de dotar o município de condições de infraestrutura básica e de serviços, além de prover estratégias de valorização da tradição popular, com vistas a consolidar Alcântara como destino turístico no mercado.

Palavras chave: Turismo; Festa popular; Festa do Divino Espírito Santo, Alcântara (MA).

ABSTRACT - In this paper is analyzed the tourism potential of "Festa do Divino Espírito Santo" in Alcântara (Maranhão - Brazil). In the understanding of the relationships between popular festivals and tourism, it was used the qualitative research with descriptive character, based on published reports and interviews with the organizers of the festival. Based on Guarinello (2001), Rangel (2002) and Hall (2001), the study lists the memory and identity concepts, presenting the positive and negative impacts of tourism in popular culture. It was analyzed the dynamics of "Festa do Divino" at the time that it demonstrates the possibilities and challenges of this cultural manifestation as a tourist product from Alcântara (Maranhão - Brazil). The research pointed to the need of promoting to the city basic infrastructure and services conditions, as well as providing recovery strategies of popular tradition, in order to consolidate Alcântara as a tourism destination.

Key words: Tourism; Popular festival; Festa do Divino Espírito Santo, Alcântara (MA Brazil).

\footnotetext{
* Formação: Graduação em Turismo pela Universidade Estadual do Maranhão (UFMA), Mestrado em Cultura e Turismo pela Universidade Estadual de Santa Cruz (UESC), Ilhéus, Bahia. Atividade profissional: Docente do Curso de Turismo da Universidade Federal do Maranhão (UFMA), Campus São Bernardo, Maranhão. Endereço físico para correspondência: Rua Barão do Rio Branco, Quadra i, número 14, Sítio Leal, Bairro Filipinho. CEP: 65045-340 - São Luís - Maranhão (Brasil). Email: karolinydiniz@gmail.com
} 


\section{INTRODUÇÃO}

No presente artigo se analisa o potencial turístico da Festa do Divino Espírito Santo no município de Alcântara, Maranhão. Demarcadora da memória e da identidade do ser alcantarense, a Festa do Divino constitui-se principal atrativo turístico da cidade; durante a realização desse evento popular, o município de Alcântara recebe um fluxo expressivo de visitantes (COSTA, 2011), os quais engendram uma rede de relações sociais, culturais e econômicas que movimentam o cotidiano da antiga cidade colonial.

Embora haja inúmeros estudos que retratam a organização da Festa do Divino, poucos são aqueles cuja análise enfatiza o seu potencial turístico; ainda, constatou-se a carência de dados e/ou indicadores a partir dos quais se possa ser mensurado o grau de importância da Festa do Divino para a consolidação do turismo local. Essas constatações estimularam a opção de analisar a Festa do Divino como objeto de estudo, tentando compreender o seu potencial e importância para o turismo.

Assim, o objetivo geral do estudo consistiu em compreender a Festa do Divino como atrativo turístico de Alcântara, Maranhão. Enquanto desdobramentos ou objetivos específicos se buscaram: 1) relacionar festas populares e turismo; 2) descrever as etapas inerentes à Festa do Divino e 3) averiguar o seu potencial para o turismo.

O estudo foi voltado para o entendimento da festa popular como suporte de memória e de identidade e suas relações com o turismo por meio de uma abordagem qualitativa. Enquanto procedimentos teórico-metodológicos buscou-se a realização de pesquisa bibliográfica de caráter descritivo e exploratório e de pesquisa de campo, mediante entrevistas informais junto aos principais organizadores da Festa do Divino em Alcântara.

Na teorização dessa pesquisa, as contribuições de Brant (2003), Mcdowell (2007) e Geertz (1989) sobre cultura; Rangel (2002) e Hall (2001) acerca da memória e das identidades respectivamente, e de Guarinello (2001) sobre festa popular como produto do cotidiano, foram importantes para a compreensão do tema e para se entender a dinâmica dos processos culturais que enredam a trama da Festa do Divino em Alcântara. A abordagem sobre o turismo foi estruturada a partir das considerações de Banducci Jr e Barretto (2001) e Dias (2006). 
Os autores Lima (1998) e Rocha (2008) foram os referenciais teóricos a partir dos quais procurou-se desvendar as especificidades e simbologias envoltas da Festa do Divino Espírito Santo, seus rituais e principais momentos, nos quais a mobilização e a participação comunitária são características essenciais para a manutenção desse legado cultural.

A análise em torno da Festa permitiu a abordagem de seu potencial enquanto produto turístico, identificando as possibilidades e principais entraves ao aproveitamento da Festa do Divino enquanto principal produto turístico a ser comercializado em Alcântara.

Assim, o estudo acerca do potencial turístico da Festa do Divino em Alcântara, bem como da participação e interação da comunidade local no âmbito do evento popular tornam-se significativos para os futuros gestores dessa atividade, a fim de que os mesmos possam vislumbrar novas possibilidades de incremento da oferta turística. Ainda, para a comunidade, o registro das etapas da Festa do Divino no contexto turístico contribui sobremaneira para a socialização de informações sobre as características dessa manifestação, estimulando o desenvolvimento de novas pesquisas em torno da Festa e suas motivações.

\section{A RELAÇÃO ENTRE FESTAS POPULARES E TURISMO}

Todo e qualquer grupo social se define pelos elementos que o particularizam em relação aos outros, os quais permitem a identificação e o reconhecimento dos seus membros enquanto partícipes de uma dinâmica comum. As crenças, os modos de vida comunitários, os elos de afetividade em relação a uma história em comum, as tradições religiosas, e outros aspectos da realidade econômica, cultural e social que são aprendidos pelos membros de uma dada comunidade podem ser entendidos como cultura.

Para Brant (2003, p. 3), cultura pode ser definida como "um conjunto de características espirituais, materiais, intelectuais e afetivas distintas, que caracterizam uma sociedade ou um grupo social.” Já Mcdowell (2007, p. 161), define cultura da seguinte forma:

Turismo \& Sociedade (ISSN: 1983-5442). Curitiba, v. 9, n. 1, p. 1-18, janeiro-abril de 2016. 
[...] conjunto de idéias, hábitos e crenças que dá forma às ações das pessoas e à sua produção de artefatos materiais, incluindo a paisagem e o ambiente construído. A cultura é socialmente definida e socialmente determinada. Idéias culturais são expressas nas vidas de grupos sociais que articulam, expressam e contestam esses conjuntos de idéias e valores, que são eles próprios específicos no tempo e no espaço.

Geertz (1989, p. 64) por sua vez apresenta uma visão semiótica da cultura, sendo esta entendida como o universo simbólico, uma teia de significados, um texto que orienta as ações humanas em sociedade, "tornar-se humano é tornar-se individual, e nós nos tornamos individuais sob a direção dos padrões culturais, sistemas de significados criados historicamente em termos dos quais damos forma, ordem, objetivo e direção às nossas vidas".

No universo diversificado da cultura, interessa a essa investigação os diferentes significados e dimensões das festas populares, bem como as relações que elas engendram com a atividade turística. Existem muitos posicionamentos teóricos sobre a categoria festa; alguns autores entendem a festa como momento apartado do cotidiano, que emerge em oposição a ele, gerando outro tempo e espaço, outro ritmo, outros personagens (DUVIGNAUD, 1977; DAMATTA, 1990; PEREZ, 2002).

Outros teóricos entendem a festa não em oposição ao cotidiano, mas como fenômeno integrado a ele (CANCLINI, 1982; GUARINELLO, 2001), uma vez que o momento festivo ocorre porque existe o seu contrário. Um torna possível a existência do outro. Tendo como eixo orientador a concepção de Guarinello (2001, p. 972) entende-se festa como:

[...] uma produção do cotidiano, uma ação coletiva, que se dá sempre num tempo e espaço definidos e especiais, implicando a concentração de afetos e emoções em torno de um objeto que é celebrado e comemorado e cujo produto principal é a simbolização da unidade dos participantes na esfera de uma determinada identidade. Festa é um ponto de confluências das ações sociais cujo fim é a própria reunião ativa de seus participantes.

A definição de festa proposta por Guarinello (2001) torna-se pertinente ao indicar que uma festa é uma realidade polifônica. Assim, com base ainda nesse autor, as festas populares são entendidas no contexto dessa pesquisa como momentos de celebração comunitária que evocam diferentes memórias - individuais e coletivas sendo referenciais para a afirmação da identidade de um grupo (RANGEL, 2002). 
Hall (2001) esclarece que na pós-modernidade as identidades estão em constante mudança ou transformação, sendo preferível adotar o termo identificação para buscar o entendimento de que as identidades não são fixas, pelo contrário, são móveis. Significa afirmar que existem referências culturais que são tomadas de empréstimo pelos grupos sociais dependendo do contexto ou da situação.

Sendo a cultura dinâmica, ao longo do tempo os grupos sociais vão modificando os elementos considerados originais de um ritual ou dança, festa ou celebração religiosa, reelaborando muitas vezes os seus significados, ou agregando "inovações" às tradições populares que se modernizam como estratégia de sobrevivência em novos contextos sociais.

Com base nesse quadro geral, pôde-se delimitar outra característica das festas populares. Elas são ao mesmo tempo espaços materiais e simbólicos carregados de afetividade, onde há a circulação de objetos, artefatos entre os membros de uma comunidade e exterior a ela; Momentos da vida em sociedade nos quais se evidenciam os laços de solidariedade, de reciprocidade e de sociabilidade, e ainda, de reafirmação das identidades (MAZOCO, 2007).

Nas ocasiões festivas, as ações são pautadas em elementos materiais ou intangíveis que expressam o agir e o sentir dos grupos. No caso das manifestações religiosas, as festas significam os momentos em que "a sociedade homenageia, honra ou rememora personagens, símbolos ou acontecimentos com os quais ela se identifica" (TRIGUEIRO, 2007, p. 107).

Nas festas e acontecimentos religiosos - romarias e peregrinações, rituais em homenagem a santos católicos e padroeiros, dentre outros, coexistem momentos sagrados e profanos, de trabalho e de lazer. No âmbito do turismo, as festas populares são identificadas como importantes atrativos, gerando interesse de visitantes que buscam entrar em contato com os aspectos imateriais da cultura.

De acordo com Menezes (2003, p. 6) "as dramatizações, realizações de bailes e musicais, celebração de festas populares e religiosas são algumas atividades que valorizam a experiência do visitante no lugar. Logo, todas estas manifestações tornamse objetos do turismo".

É por meio das festas populares que o turista cultural exerce o principal objetivo da visitação, o qual consiste em entrar em contato e vivenciar aspectos do patrimônio 
cultural. No entanto, nem sempre a relação entre turismo e festas populares ocorre de forma criteriosa. A depender da forma como que é entendida e planejada a atividade turística, a presença de visitantes pode trazer malefícios à cultura local.

Conforme observam alguns autores, o turismo possui um caráter pedagógico que possibilita a compreensão intercultural (DIAS; AGUIAR, 2002; IGNARRA, 2003). A transformação da festa em produto turístico possibilita que a comunidade local perceba a sua importância não apenas pela questão econômica, mas como elemento de identidade. Assim, a valorização das festas populares, o orgulho cultural são um dos principais benefícios acarretados pelo e para o turismo.

Nesse caso, não apenas o elemento festa se beneficia, mas toda a rede de relações que nela estão envolvidas: a gastronomia, o artesanato, os saberes e fazeres, ou seja, as atividades que possibilitam o acontecimento - a festa - numa comunidade acabam sendo estimuladas pelo e para o turismo. A cadeia produtiva que envolve a festa é dinamizada e reflete-se numa maior motivação das pessoas em dar continuidade aos festejos populares. O turismo confere visibilidade aos bens materiais ou imateriais alçados à condição de produtos turísticos.

No entanto, a relação turismo e cultura nem sempre ocorre de forma harmoniosa e, em se tratando das festas populares, há que se pensar nos efeitos negativos dessa relação (DIAS; AGUIAR, 2002; IGNARRA, 2003; LAGE; MILONE, 2000). Ao se transformarem em produto turístico, muitas manifestações, principalmente as religiosas, podem vir a sofrer adaptações e serem apresentadas aos visitantes fora do contexto original onde estão inseridas. Muitos teóricos da área de turismo vêm analisando a denominada mercantilização ou mercadorização da cultura para fins turísticos, notadamente no âmbito dos rituais, festas e celebrações religiosas, que podem perder seus elementos sagrados e se transformar em objetos de entretenimento turístico.

Ao se assumir que as culturas são dinâmicas, então não seria o turismo o agente principal dessas transformações, as quais muitas das vezes se tornam necessárias para que uma manifestação sobreviva no mercado. No entanto, o que se discute é o nível de interferência do turismo e de outros fenômenos sociais, como a globalização, na dinâmica própria da cultura popular.

Quando as modificações são criações a partir de uma comunidade, então as mudanças passam a ser aceitas e se tornam coletivas, passando a fazer parte das demais 
tradições; a partir do momento em que elas são impostas ou vistas como necessárias apenas em virtude de uma relação comercial, aí se tem um elemento prejudicial à sua sobrevivência e continuidade.

Diante do quadro geral esboçado acima, se direcionou o olhar da presente pesquisa ao município de Alcântara, Maranhão, tendo como objeto de análise verificar o potencial turístico da Festa do Divino Espírito Santo.

\section{A FESTA DO DIVINO ESPÍRITO SANTO EM ALCÂNTARA (MA)}

Localizada no litoral ocidental maranhense, Alcântara dista trinta quilômetros da capital, São Luís, fazendo parte da região metropolitana da capital (FIGURA 1). Possui uma área de 1.457,916 quilômetros quadrados, tem na sua localização geográfica privilegiada, próxima à linha do Equador, um de seus diferenciais (IBGE, 2010).

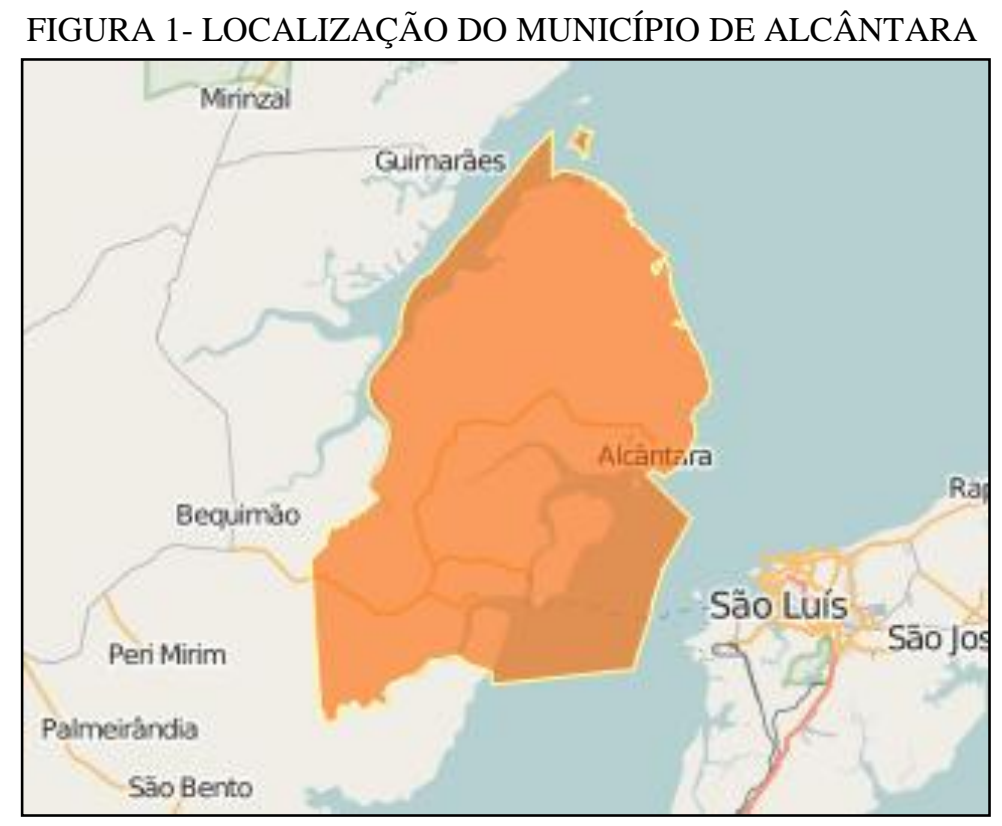

FONTE: IBGE (2015).

Situa-se na mesorregião norte do Maranhão, e na microrregião litoral ocidental maranhense, a exatos $2^{\circ} 24^{\prime \prime}$ de latitude e $44^{\circ} 25^{\prime}$ de longitude, fazendo divisa com o oceano Atlântico ao norte, com a baia de Cumã ao sul, com os municípios de São Luis e 
Cajapió a leste e com os municípios de Bequimão, Guimarães e Peri-Mirim a oeste, segundo o Instituto Brasileiro de Geografia e Estatística - IBGE (2010).

Os processos históricos e culturais pelos quais a cidade de Alcântara passou ao longo dos anos contribuíram para a materialização de um conjunto de referências que configuram não apenas o espaço urbano local, ou seja, seu conjunto históricoarquitetônico, mas o estilo de vida, hábitos e costumes específicos de seus moradores. Esses elementos formam a memória urbana e estão presentes nos casarões históricos, nas ladeiras, praças e ruas de Alcântara, e nas formas de saber-fazer específicas.

$\mathrm{Na}$ cidade de Alcântara, as produções culturais evidenciam-se nos espaços públicos, como os museus, as praças, as ruas, que se tornam cenários de exibição da cultura popular. Festas e celebrações populares atualizam a memória local, ao tempo em que surgem como elementos de reafirmação de uma identidade, pois trazem consigo uma forte carga simbólica para quem delas participam - sejam pessoas da comunidade ou externas a ela.

De acordo com Silva (1998), na época do Brasil colônia, casais açorianos foram enviados para povoar diversas regiões costeiras pertencentes às capitanias hereditárias, principalmente Maranhão e Bahia. E através desses colonizadores foram sendo introduzidos costumes e crenças religiosas que, a partir da expansão territorial portuguesa, difundiram-se pelo país. Portando, várias manifestações religiosas foram trazidas pelos europeus para o Brasil, uma delas foi à Festa do Divino Espírito Santo que ainda é preservada com diversas características.

A Festa do Divino Espírito Santo teve sua origem em Portugal com a construção da igreja do Divino Espírito Santo em Alenquer, determinada pela Rainha Isabel, no século XVIII; chegou ao Brasil no século XVI e ganhou popularidade e prestígio em nível nacional especialmente no Rio de Janeiro, São Paulo, Minas Gerais, Paraná, Santa Catarina, Goiás e Maranhão (LIMA, 1988).

A festa realiza-se em todo o Estado do Maranhão, notadamente na cidade de Alcântara; inicia-se na véspera da Ascensão e se encerra no domingo de Pentecostes. (ROCHA, 2008). Manifestação esta em que se comemora a descida do Espírito Santo sobre os Apóstolos, quando após a procissão do Divino, o vigário paroquial faz a leitura dos nomes das pessoas escolhidas para fazerem a festa do ano seguinte (ROCHA, 2008). 
Em Alcântara não há informações precisas de quando começou a referida festa. Várias são as versões apresentadas pelos moradores mais velhos. Dizem que teve inicio quando da frustrada visita de Dom Pedro II; então os negros, decepcionados, levaram um cortejo à igreja, coroando um imperador e inventando a festa (LIMA, 1988, p. 21). Não obstante Rocha (2008, p. 18), assinala que a Festa do Divino é:

[...] um evento caracteristicamente maranhense, que está presente em todo o estado e durante o ano todo, e que conta com devotos e participantes que atingem todas as faixas etárias, de crianças a idosos. Motivo recorrente nas memórias dos mais velhos, que lamentam as tradições perdidas, e razão de ansiedade para crianças e jovens que sonham com a experiência de conduzir simbolicamente um império, a festa do divino oferece razões mais do que suficientes para ser melhor conhecida e estudada em todos os seus aspectos, inclusive sobre os aspectos linguísticos que tem a revelar.

A Festa do Divino é uma manifestação na qual se reúnem diversas formas de sagração ao santo, como rituais, as folias, os cortejos, as correspondências, a musicalidade das caixeiras, a partilha do pão em volta da mesa (COSTA, 2011). É uma festa onde o sagrado e o profano se mesclam de forma harmoniosa fazendo com que Alcântara se transforme num grande cenário histórico e cultural, tudo isso e somente para receber os principais personagens do império do Divino ${ }^{1}$ (FIGURA 2).

FIGURA 2- CORTEJO DO DIVINO EM ALCÂNTARA
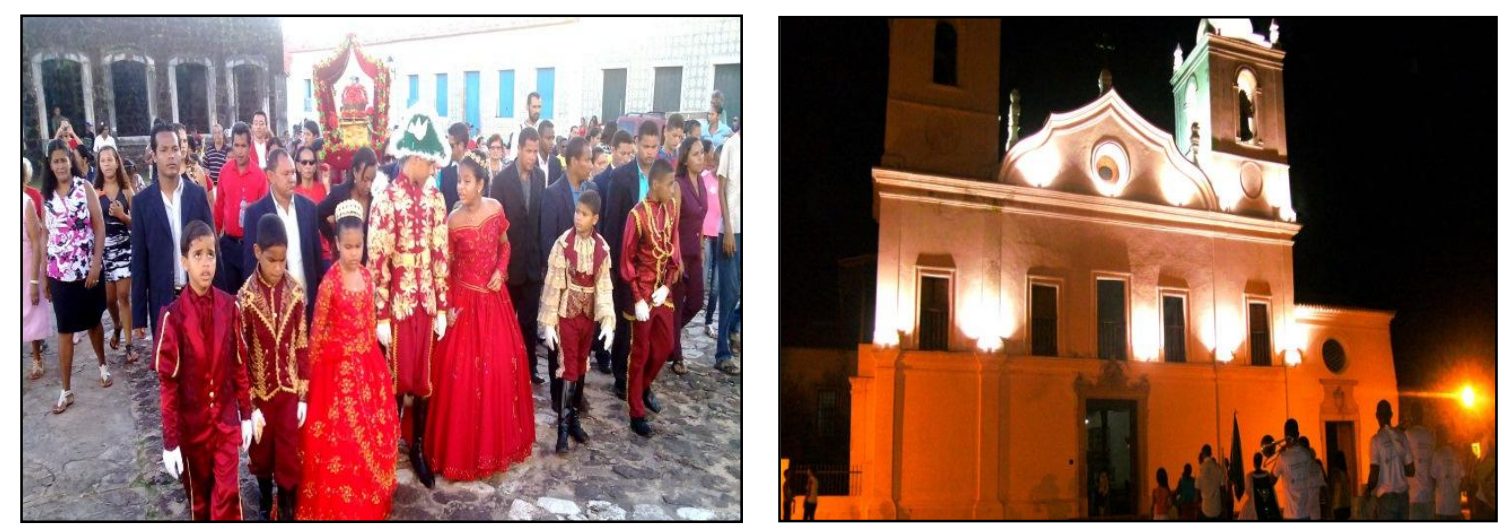

FONTE: COSTA (2011).

De acordo com Frugoli e Bueno (2014, p. 139) “observa-se no calendário de festividades coloniais, além dessa ligação sagrado/profano, num sentido mais amplo a

\footnotetext{
${ }^{1}$ Informação verbal concedida pelo Sr Moacir, um dos organizadores da Festa do Divino.
} 
produção da memória coletiva e, portanto, de identidade no tempo e no espaço", fato que se verifica na dinâmica do festejo do Divino em Alcântara.

Cada festeiro (Imperador, Mordomo-Régio, e Mordomos-Baixos) tem seu séquito, a começar por seu próprio representante. Porque não é a pessoa escolhida que comparece a todos os festejos, mas seu representante, menino (a), criança, ou adolescente. O Imperador festeiro representado pelo Imperador do trono, geralmente seu filho, neto e aparentado, um menino fardado de branco, com alamares, ou botões, dourados, manto vermelho e coroa. Faz-se acompanhar de dois vassalos para a Imperatriz e aias e um vassalo, à frente, o estandarte vermelho (LIMA, 1988).

As caixeiras são mulheres simples, geralmente idosas, e chamam atenção por sua resistência à fadiga, nas longas caminhadas e constantes vigílias durante a festa (ROCHA, 2008), onde o tocar das caixeiras é reconhecível a distância por suas a cantigas peculiares, onde dão um ar especial (LIMA, 1988).

Em Alcântara, constatou-se que a festa mobiliza toda a comunidade e transforma o espaço da cidade, a qual é organizada para o evento e recebe um fluxo intenso de visitantes, tanto de turistas como de devotos. É, conforme observado uma festa de pagamento de promessas, uma festa de doação, não só dos alimentos distribuídos, mas do tempo utilizado na preparação da festa, na decoração das casas e ruas, na confecção dos licores e doces. A respeito do pedido de graças e consequente de promessas, evidenciado nos cânticos das caixeiras.

Constatou-se que a Festa do Divino é um momento de celebração da religiosidade, de lazer, mas que apresenta momentos de trabalho e obrigações para com a festa, pois durante os trezes dias de festa se tem um espaço de circulação das indumentárias, na exposição dos doces e dos altares, nos símbolos expostos no local, seja nos rituais das visitas, seja nas demais representações simbólicas da identidade do festejo que contribui para o conhecimento acerca dos sentidos e significados das festas populares. 


\section{POTENCIAL TURÍSTICO DA FESTA DO DIVINO}

A Festa constitui-se num dos eventos profano-religiosos mais importantes do estado do Maranhão, atraindo um grande número de turistas, principalmente de São Luís, Pinheiro, São Bento, Barreirinhas e demais Estados. Constatou-se que o calendário de festas religiosas atrai visitantes ao longo do ano, o que aquece o comércio local com pequenas pousadas, restaurantes, bares e comércio em geral. Nos festejos do Divino, por exemplo, o comércio ambulante é visível, as praças das igrejas transformam-se em pequenos largos de quermesse.

Nesse sentido, a Festa do Divino Espírito Santo pode ser considerada o principal elemento da oferta turística de Alcântara, ao lado dos demais atrativos existentes na cidade. Por meio da observação direta deste festejo, identificou-se que os turistas e visitantes entram em contato com os aspectos da realidade socioeconômica do lugar: as práticas cotidianas, o estilo de vida, e os componentes da gastronomia local.

Paralelo ao conjunto de rituais de sagração ao Divino Espírito Santo está outra atividade totalmente profana, festiva e de cunho puramente comercial que acontece em praça pública e em clubes de reggae, e que se intensificou a partir da década de 1980, quando a festa passou a ser vista pela própria comunidade alcantarense como um incremento na economia familiar. Nas duas principais praças de Alcântara, comerciantes autônomos montam barracas para a comercialização de bebidas e comidas (LIMA, 1988; ROCHA, 2008; COSTA, 2011).

Enquanto principal produto turístico se pôde realizar, a partir da matriz SWOT (pontos fortes, pontos fracos, ameaças e oportunidades), uma análise da Festa do Divino Espírito Santo, a fim de identificar o seu potencial para o desenvolvimento da atividade turística (QUADRO 1):

QUADRO 1 - MATRIZ SWOT DA FESTA DO DIVINO

\begin{tabular}{ll|ll}
\hline \multicolumn{1}{c|}{ Pontos Fortes } & \multicolumn{1}{c}{ Pontos fracos } \\
\hline - $\begin{array}{l}\text { Manutenção e valorização da tradição pelos } \\
\text { moradores locais }\end{array}$ & $\bullet$ & Acessibilidade ao município \\
\hline $\begin{array}{l}\text { Dinâmica do Festejo estimula a } \\
\text { participação dos turistas e espectadores } \\
\text { (missa, levantamento do mastro, visitas dos } \\
\text { mordomos etc.) }\end{array}$ & $\bullet \begin{array}{l}\text { Deficiência na infraestrutura básica de } \\
\text { serviços e equipamentos turísticos }\end{array}$ \\
\hline $\begin{array}{l}\text { Existência de local para exposição e } \\
\text { divulgação da Festa do Divino }\end{array}$ & $\bullet \quad \begin{array}{l}\text { Falta de interesse do público jovem em } \\
\text { aprender o ofício das caixeiras }\end{array}$ \\
\hline
\end{tabular}


Continuação.

\begin{tabular}{|c|c|}
\hline $\begin{array}{l}\text { Existência de Secretaria de Cultura e de } \\
\text { Turismo visando o apoio à realização da } \\
\text { Festa }\end{array}$ & 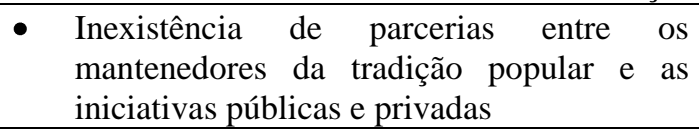 \\
\hline $\begin{array}{l}\text { - Iniciativas locais em } \begin{array}{l}\text { prol do } \\
\text { reconhecimento da Festa } \\
\text { patrimônio imaterial nacional }\end{array} \\
\text { enquanto }\end{array}$ & $\begin{array}{l}\text { - Ausência de um roteiro turístico religioso } \\
\text { entre os municípios que compõem o } \\
\text { denominado Polo turístico São Luís (São } \\
\text { Luís, Raposa, Alcântara, São José de } \\
\text { Ribamar e Paço do Lumiar) }\end{array}$ \\
\hline $\begin{array}{l}\text { - Diversidade gastronômica e dinamização da } \\
\text { economia a partir do festejo popular }\end{array}$ & $\begin{array}{l}\text { - Ausência de ações de registro e de } \\
\text { acompanhamento das etapas que compõem } \\
\text { a Festa do Divino }\end{array}$ \\
\hline Ameaças & Oportunidades \\
\hline $\begin{array}{l}\text { - Fraca divulgação do festejo pelos governos } \\
\text { estadual e municipal }\end{array}$ & $\begin{array}{l}\text { - Aumento do interesse dos turistas pelos } \\
\text { aspectos culturais do lugar visitado }\end{array}$ \\
\hline $\begin{array}{l}\text { - Distância do município de Alcântara dos } \\
\text { principais mercados emissores de turistas } \\
\text { em nível nacional }\end{array}$ & $\begin{array}{l}\text { Programas de apoio às iniciativas de } \\
\text { valorização das culturas populares }\end{array}$ \\
\hline $\begin{array}{l}\text { - Nível de competitividade dos principais } \\
\text { destinos concorrentes }\end{array}$ & $\begin{array}{l}\text { - Estímulo à consolidação de parcerias entre } \\
\text { as diversas instâncias governamentais e o } \\
\text { setor privado }\end{array}$ \\
\hline $\begin{array}{l}\text { - Ausência de articulação entre as secretarias } \\
\text { municipais de cultura e turismo e as } \\
\text { secretarias estadual de cultura e de turismo } \\
\text { para a realização de projetos de valorização } \\
\text { da Festa do Divino (realização de oficinas, } \\
\text { encontros e seminários temáticos) }\end{array}$ & $\begin{array}{l}\text { - Valorização econômica da cultura popular } \\
\text { (reconhecimento do setor da cultura na } \\
\text { formação do Produto Interno Bruto - PIB e } \\
\text { para o desenvolvimento socioeconômico } \\
\text { local) }\end{array}$ \\
\hline
\end{tabular}

FONTE: Pesquisa de campo, 2015.

Com base nos aspectos sintetizados na matriz, constatou-se que a Festa do Divino possui potencial como elemento de atratividade turística, sendo uma tradição popular que é revivida e resignificada pelos moradores, os quais consideram a Festa um importante elemento de religiosidade, além de patrimônio afetivo, tendo em vista que através dela podem ser rememorados elementos da identidade de um grupo e da memória social.

O apreço dos moradores é revelado nas etapas que precedem o evento, nas quais se evidenciou a mobilização popular em torno da confecção dos trajes, dos altares, na preparação dos doces e licores, e demais eventos que garantem a sua realização. A festa conta ainda com o apoio das Secretarias estadual e municipal. No entanto, existem alguns entraves para que a Festa se configure como produto turístico com elevado nível de competitividade, sobretudo no que se refere ao conjunto de equipamentos, bens e serviços urbanos e turísticos disponíveis no município.

A ida de visitantes nos períodos festivos é complexa, considerando os problemas de embarcações. Observou-se que a falta de segurança e infraestrutura dos transportes e 
de hotelaria causam transtornos aos visitantes. Constatou-se que a demanda de moradores e turistas se torna maior, o que congestiona trânsito e rede hoteleira. Entretanto apesar das dificuldades constatadas, o caos atrai curiosos que continuam a aventura em perigosas travessias para participação de festejos e de grandes festas de radiola de reggae.

Com base na pesquisa de campo realizada, identificou-se que o intenso fluxo de visitantes durante a Festa do Divino evidencia a carência de infraestrutura básica e de serviços necessárias para que o turismo possa se desenvolver com qualidade. Além da dificuldade de acesso, observou-se que o município não dispõe de um conjunto de equipamentos, bens e serviços turísticos capazes de atender à expectativa da demanda ao longo da realização da Festa e em outros acontecimentos de caráter turístico local.

Constatou-se que mesmo com as dificuldades apresentadas, a complexidade das etapas que envolvem este evento religioso estimula a participação ativa dos visitantes: no levantamento do mastro, nas missas e ladainhas, na visita aos mordomos, ou seja, os espaços de convivência comunitária transformam-se em espaços materiais e simbólicos onde bens, serviços, patrimônios e elementos da cultura circulam entre anfitriões e hóspedes. Por meio da observação direta do festejo pôde-se identificar que o turismo mantém viva a circularidade da Festa do Divino Espírito Santo.

Circularidade que dinamiza o setor econômico do município. Constatou-se que ao longo dos dias de realização da Festa, os bares, hotéis, restaurantes, clubes de reggae e o comércio informal são movimentados, através dos quais os membros da comunidade local elevam sua renda e, consequentemente, sua expectativa de vida:

\footnotetext{
O turismo é uma força econômica das mais importantes do mundo. Nele ocorrem fenômenos de consumo, originam-se rendas, criam-se mercados nos quais a oferta e a procura encontram-se. Os resultados do movimento financeiro decorrentes do turismo são por demais expressivos e justificam que esta atividade seja incluída na programação da política econômica de todos os países (OLIVEIRA, 2002, p. 45).
}

Outro aspecto positivo refere-se à valorização do festejo pelos moradores. $\mathrm{O}$ sentimento de pertencimento à Festa do Divino faz-se presente, sobretudo, entre as pessoas mais idosas, cuja memória individual recompõe-se por meio da memória coletiva. A Festa é em si o lugar social que o indivíduo ocupa na sociedade alcantarense. Muitos são os personagens que vivenciam a Festa do Divino mesmo após 
o término do ciclo festivo, uma vez que ela está arraigada aos hábitos, costumes e valores identitários locais (ROCHA, 2008).

A presença da Casa do Divino ${ }^{2}$ reforça essa assertiva, por se tratar de um espaço de aprendizado e de intercâmbio e informações sobre o festejo e importante atrativo para o turismo local. As Secretarias de Turismo e de Cultura podem servir de estímulo para iniciativas de valorização e de reconhecimento desse aspecto da cultura popular enquanto patrimônio imaterial nacional. Observou-se já existirem articulações no sentido de solicitar ao Instituto do Patrimônio Histórico e Artístico Nacional - IPHAN, o registro da Festa do Divino.

O estabelecimento de parcerias deve ser estimulado, com vistas à realização de projetos e ações de fortalecimento da identidade e da memória do lugar, e de preservação dos bens culturais - materiais e intangíveis - existentes no município de Alcântara.

É notória a mobilização e participação dos diferentes segmentos sociais na dinâmica da festa, conforme apontado anteriormente, no entanto, a discussão em torno da transmissão e do repasse dos saberes e fazeres dos mestres da cultura popular local, tais como o ofício das caixeiras do Divino e da confecção dos altares, ainda não está sendo aprofundada pelos moradores da cidade. Percebeu-se existir iniciativas isoladas de valorização de um dos principais símbolos do Festejo - as Caixeiras - de forma pontual, esporádica e não permanente.

Nesse sentido, devem ser criadas condições de transmissão do legado da Festa do Divino nas instituições formais e informais do ensino, bem como ser estimulada a realização de fóruns para debates, discussões e acompanhamento da dinâmica da festa popular no contexto do turismo e da globalização. Dias (2006) alerta que:

\begin{abstract}
Se uma manifestação cultural popular não apresentar pessoas que integram a comunidade retratada, ela não poderá reforçar a identidade cultural dessa comunidade, pois não existe a condição fundamental da continuidade existência de integrantes da cultura local - da manifestação tradicional. [...] a participação de membros da comunidade na manifestação é condição necessária para que cumpra sua função social de fortalecer a identidade do grupo.
\end{abstract}

\footnotetext{
${ }^{2}$ A Casa do Divino está localizado no casarão à Rua Grande e abriga acervo sobre a Festa do Divino: altares, caixas, tronos. Durante a realização do festejo transforma-se na residência oficial do Imperador ou da Imperatriz.
} 
Outro ponto a ser destacado refere-se à necessidade de se ampliar a divulgação do Festejo enquanto estratégia de inserção da cidade de Alcântara no setor turístico. Há a necessidade de estimular as parcerias e alianças entre os atores que interagem direta e indiretamente na Festa do Divino - festeiros e empresários do setor turístico, gestores públicos e comunidade em geral - a fim de que se estabeleçam projetos de valorização, de registro e de acompanhamento da dinâmica da Festa popular.

O objetivo principal das parcerias seria contribuir para a continuidade dessa prática e para a valorização dos mestres populares locais: "o dilema, contudo, é que os benefícios obtidos com o turismo também fornecem os meios para criar ou expandir os festivais, restaurar e cultivar tradições e fomentar e repartir o espírito comunitário" (GETZ, 2001, p. 424).

Cabe enfatizar que para a consolidação da Festa do Divino enquanto produto turístico seria fundamental a realização de ações visando à melhoria da estrutura da cidade, em termos de acessibilidade, assistência médico-hospitalar, qualificação nas áreas de hospitalidade para o devido atendimento aos turistas/visitantes.

Destacam-se ainda as ações de marketing turístico voltadas para a comunicação junto ao público alvo do festejo, confecção de um banco de dados sobre o perfil do turista de Alcântara, além de estimular junto aos demais municípios do Polo São Luís São Luís, São José de Ribamar e Paço do Lumiar - a formatação de um roteiro turístico religioso de forma integrada, a fim de que a Festa do Divino se converta de fato num instrumento de dinamização da economia local e de valorização da memória e da identidade da comunidade alcantarense.

\section{CONSIDERAÇÕES FINAIS}

O espaço urbano de Alcântara, Maranhão, é permeado por memórias e identidades que se manifestam na diversidade de práticas socioculturais e especialmente nos acontecimentos religiosos, como exemplifica a Festa do Divino Espírito Santo. Tradição herdada pelos portugueses e que ganhou nuances locais, a Festa é um importante componente da cultura local, sendo traduzida ainda como fator de propulsão da atividade turística. 
A atratividade da Festa do Divino gera possibilidades para o desenvolvimento dessa localidade, posto que muitos turistas visitam a cidade durante o mês de maio, movimentando setores da economia que mantém uma relação direta e indireta com o turismo. A Festa é carregada de representações e revela os modos de ser, a visão de mundo, e a relação da comunidade com o sagrado, sua história e suas tradições locais.

O estudo sobre a Festa do Divino na perspectiva do turismo permitiu delinear a sua importância para a comunidade e como recurso econômico, seu potencial para essa atividade. De fato, se pode afirmar que a Festa se posiciona como o principal fator de motivação para o desenvolvimento do turismo, no entanto, conforme observado se faz fundamental a existência de elementos que tornem a festa uma experiência única para os visitantes.

O principal aspecto abordado pela pesquisa em questão foi a verificação do potencial turístico dessa manifestação cultural, realizando uma análise do diagnóstico das condições que poderiam ser estimuladas para incremento da festa enquanto produto de consumo turístico. Diante da metodologia empregada, concluiu-se que a Festa estava detendo um potencial turístico que precisaria ser aproveitado de forma sustentável.

A competitividade no turismo é inerente, sendo assim, caberia aos setores envolvidos desenvolverem um conjunto de estratégias que transformem a Festa do Divino Espírito Santo num produto turístico de qualidade, a partir da compreensão de sua dinâmica e importância como elemento da identidade cultural local.

Os turistas culturais são aqueles grupos que querem manter um contato mais aprofundado com as regiões visitadas, e no caso de Alcântara, verificou-se que possui atrativos potenciais capazes de complementar o produto turístico principal da cidade - a Festa do Divino. Nesse sentido, seria mister desenvolver a oferta turística de forma integral - atrativos, acesso e facilidades turísticas - de modo que o turismo gere alternativas de renda para a comunidade e constitua um fator de valorização do patrimônio cultural de Alcântara.

A realização de novas pesquisas e estudos em complementação aos já realizados poderá apontar a conveniência da parceria entre o turismo e os eventos ou festejos religiosos, no sentido de alcançar o principal objetivo do turismo enquanto fenômeno: contribuir para a elevação da qualidade de vida dos moradores a partir do intercâmbio cultural, do encontro das diferenças e do estabelecimento de relações breves, porém, 
significativas para o desenvolvimento das relações socioculturais diante das práticas de hospitalidade.

\section{REFERÊNCIAS}

BANDUCCI JR. Á.; BARRETTO, M. Introdução. In: BANDUCCI JR. Á.; BARRETTO, M. (Orgs.). Turismo e Identidade Local: uma visão antropológica. Campinas, SP: Papirus, 2001, p. 07-20.

BRANT, L. Políticas culturais. Barueri, SP: Manole, 2003. v. I, p. 142.

CANCLINI, N. G. As culturas populares no capitalismo. São Paulo: Brasiliense, 1982.

COSTA, R. S.C. O culto, a nobreza, o sagrado e o lazer: representações Sociais no Cerimonial da Festa do Divino em Alcântara - MA. 2011. 87 f. Monografia. [Monografia de Turismo]. Universidade Federal Maranhão, São Luís, 2011.

DAMATTA, R. Carnavais, malandros e heróis: para uma sociologia do dilema brasileiro. Rio de Janeiro: Guanabara Koogan, 1990.

DIAS, R.; AGUIAR, M. R. Fundamentos do turismo. Campinas: Alínea, 2002.

DIAS, R. Turismo e Patrimônio Cultural: Recursos que acompanham o crescimento das cidades. São Paulo: Saraiva, 2006.

DUVIGNAUD, J. Le don du rien: essai d'anthropologie de la fê te. Paris: Stock, 1977.

FRUGOLI, R.; BUENO, M. S. O Círio de Nazaré (Pará, Brasil): relações entre o sagrado e o profano. In: Turismo \& Sociedade. Curitiba, v. 7, n. 1, p. 135-155, janeiro de 2014. Dossiê: Megaeventos.

GUARINELLO, N. L. Festa Trabalho e Cotidiano. In: JANCSÓ, I., KANTOR, Í. (Orgs.). Festa: Cultura e Sociabilidade na América, São Paulo: Edusp, 2001. p.969975.

GEERTZ, C. A interpretação das culturas. Rio de Janeiro: Zahar, 1989.

GETZ, D. O evento turístico e o dilema da autenticidade. In: THEOBALD, W. F. (Org.). Turismo global. Tradução de Anna Maria Capovila, Maria Cristina Guimarães Cupertino, João Ricardo Barros Penteado. São Paulo: Senac, 2001. p. 423 - 440.

HALL, S. A identidade cultural na pós-modernidade. São Paulo: Dp\&A, 2001. 
IBGE. Instituto Brasileiro de Geografia e estatística. Censo 2010. 2010. Disponível em: <http://www.ibge.gov.br/home/estatistica/populacao/censo2010/tabelas_pdf/total_popul acao_maranhao.pdf $>$. Acesso em: 25/03/2015.

IGNARRA, L. R. Fundamentos do turismo. 2. ed. São Paulo: Pioneira Thomson Learning, 2003.

LAGE, B. H. G.; MILONE, P. C. Turismo teoria e prática. São Paulo: Atlas, 2000.

LIMA, C. de. Festa do Divino Espírito Santo em Alcântara (Maranhão). Brasilia: Fund. Nac. Pró- Memória, grupo de Alc-, 1988.

MAZOCO, E. C. Festas e artesanato em terras do Espírito Santo. Rio de Janeiro: IPHAN, CNFCP, 2007.

MCDOWELL, L. A transformação da Geografia Cultural. In: GREGORY; D.; MARTIN, R.; SMITH, G. (Org.). Geografia Humana: Sociedade, espaço e ciência social. Rio de Janeiro: [s.n.], 2007. p. 159-188.

MENEZES, J.S. O turismo cultural como fator de desenvolvimento na cidade de Ilhéus (2003). Disponível em: 〈http://www.uesc.br/icer/artigos/oturismocultural.pdf>. Acesso em: setembro de 2015.

OLIVEIRA, C. D. M. de. Turismo religioso no Brasil: construindo um investimento sociocultural. In: TRIGO, L. G. G. Análises regionais e globais do turismo brasileiro. São Paulo: Roca, 2002. p. 325 - 344.

PEREZ, L. F. Antropologia das efervescências coletivas. In: PASSOS, M. (Org.) A festa na vida: significado e imagens. Petrópolis: Vozes, 2002. p. 15-58.

RANGEL, M. M. Educação patrimonial: Conceitos sobre patrimônio cultural. Em Secretaria de Educação de Minas Gerais. Belo Horizonte, 2002, p. 18.

ROCHA, M. de F. S. A festa do Divino Espírito Santo no Maranhão: uma proposta de glossário. 2008. 163 f. Dissertação [Mestrado em Linguística]. Universidade Federal do Ceará, Fortaleza, 2008.

SILVA, M. B. N. História da família Brasil colonial. Rio de Janeiro: Nova Fronteira, 1998.

TRIGUEIRO, O. M. Festas Populares. In: GADINI, S. L., WOLTOWICZ, K. J. (Orgs.) Noções Básicas de Folkcomunicação. Ponta Grossa (PR): UEPG, 2007, p. 107-112.

Recebido em: 21-03-2016.

Aprovado em: 20-04-2016. 